\title{
Overview of Radiation Therapy for Treating Rectal Cancer
}

\author{
Bong-Hyeon Kye, Hyeon-Min Cho \\ Department of Surgery, St. Vincent Hospital, The Catholic University of Korea College of Medicine, Suwon, Korea
}

A major outcome of importance for rectal cancer is local control. Parallel to improvements in surgical technique, adjuvant therapy regimens have been tested in clinical trials in an effort to reduce the local recurrence rate. Nowadays, the local recurrence rate has been reduced because of both good surgical techniques and the addition of radiotherapy. Based on recent reports in the literature, preoperative chemoradiotherapy is now considered the standard of care for patients with stages II and III rectal cancer. Also, short-course radiotherapy appears to provide effective local control and the same overall survival as more long-course chemoradiotherapy schedules and, therefore, may be an appropriate choice in some situations. Capecitabine is an acceptable alternative to infusion fluorouracil in those patients who are able to manage the responsibilities inherent in self-administered, oral chemotherapy. However, concurrent administration of oxaliplatin and radiotherapy is not recommended at this time. Radiation therapy has long been considered an important adjunct in the treatment of rectal cancer. Although no prospective data exist for several issues, we hope that in the near future, patients with rectal cancer can be treated by using the best combination of surgery, radiation therapy, and chemotherapy in near future.

Keywords: Rectal neoplasms; Radiatiotherapy; Chemoradiotherapy

\section{INTRODUCTION}

Adjuvant treatment of colon cancer is more focused on preventing distant metastases because this disease is characterized by lower rates of local recurrence. In contrast, neoadjuvant/adjuvant therapy of stage II or stage III rectal cancer often includes locoregional treatment due to the relatively high risk of locoregional recurrence. This risk is associated with the close proximity of the rectum to pelvic structures and organs, the absence of a serosa surrounding the rectum, and technical difficulties associated with obtaining wide surgical margins at resection.

The mainstay of treatment for rectal cancer is surgery. Since, Heald et al. [1] demonstrated in 1982 better oncologic outcome by using a total mesorectal excision (TME), which resulted in local recurrence rates lower than 5\%-10\%, the TME has become

Received: April 20,2014 - Accepted: July 23, 2014

Correspondence to: Hyeon-Min Cho, M.D.

Department of Surgery, St. Vincent hospital, The Catholic University of Korea College of Medicine, 93 Jungbu-daero, Paldal-gu, Suwon 442-723, Korea

Tel: +82-31-249-7084, Fax: +82-31-247-5347

E-mail: hmcho@catholic.ac.kr

(c) 2014 The Korean Society of Coloproctology

This is an open-access article distributed under the terms of the Creative Commons Attribution NonCommercial License (http://creativecommons.org/licenses/by-nc/3.0) which permits unrestricted noncommercial use, distribution, and reproduction in any medium, provided the original work is properly cited. the standard surgical approach for treating rectal cancer at present. A major outcome of importance for rectal cancer is local control. Parallel to improvements in surgical technique, adjuvant therapy regimens have been tested in clinical trials in an effort to reduce the local recurrence rate. These trials demonstrated that the local recurrence was improved because of both good surgical techniques and the addition of radiotherapy (RT) [2-4].

Currently, although many colorectal surgeons have used RT for the treatment of rectal cancer, they have often faced situations in which they have to decide whether RT for rectal cancer should be performed preoperatively or postoperatively, by short-course or long-course, and with or without chemotherapy. Also, if they select preoperative radiation therapy, they should decide how to evaluate the tumor's response after radiation and when to perform radical surgery. In this review, for better oncologic outcomes for the treatment of rectal cancer, the authors discuss the above problems based on the published literature and introduce the results of recent clinical trials.

\section{TECHNIQUE OF RADIATION THERAPY FOR RECTAL CANCER}

The rectum is defined inferiorly from the lowest level of the ischial tuberosities (right or left); it ends superiorly before it loses its round shape in the axial plane and connects anteriorly with the 
sigmoid. Part of the anus may unintentionally be included when using this definition, which is of no concern. The AnoRectumSig includes the anus, rectum, and rectosigmoid and is a target structure in rectal cancer. The mesorectum is also a target structure in radiation planning for rectal cancers. With respect to administration of RT, multiple RT fields should include the tumor or tumor bed with a 2-or 5-cm margin, presacral nodes, and the internal iliac nodes. The external iliac nodes should also be included for T4 tumors involving anterior structures; inclusion of the inguinal nodes for tumors invading the distal anal canal can also be considered. In long-course RT, recommended doses of RT are typically 45 to 50 Gy in 25 to 28 fractions to the pelvis using 3 or 4 fields. Any boost clinical target volumes extend to the entire mesorectum and the presacral region at the involved levels, including $2-\mathrm{cm}$ cephalad and caudad in the mesorectum and $2-\mathrm{cm}$ on a gross tumor within the anorectum. Positioning and other techniques to minimize radiation to the small bowel are encouraged [5].

In preoperative short-course RT, the target volume included the anal canal, the primary tumor, the mesorectal and the presacral nodes, the lymph nodes along the internal iliac artery, the lumbar lymph nodes up to the level of the upper border of the fifth lumbar vertebra, and the lymph nodes at the obturator foramen. The treatment was, however, not individually planned for each patient; rather, the beam limits were defined by anatomic (bony) landmarks. It was delivered with three portals with the patient in a prone position or with a four-portal so-called box technique with the patient lying supine. The cranial beam limits of all beams were at the middle of the fourth lumbar vertebra, the caudal $1 \mathrm{~cm}$ below the anal verge, the ventral limits of the lateral beams approximately $3.5 \mathrm{~cm}$ in front of the promontory, and the dorsal limits behind the sacrum. The tumor dose was $25 \mathrm{~Gy}$ administered in 5 fractions over 1 week $[2,6]$.

\section{PREOPERATIVE VERSUS POSTOPERATIVE RADIATION}

Advantages that have often been associated with preoperative RT, as opposed to RT given postoperatively, are related to both tumor response and preservation of normal tissue [7-9]. First of all, reducing tumor volume may facilitate resection and increase the likelihood of a sphincter-sparing procedure [7, 8]. Second, irradiating tissue that is surgery-naive and thus better oxygenated may result in increased sensitivity to RT. Tumor cells are significantly more sensitive to an equivalent dose of RT in the presence of oxygen as opposed to hypoxic conditions [9]. Third, preoperative RT can avoid the occurrence of RT-induced injury to the small bowel trapped in the pelvis by postsurgical adhesions [7]. Finally, the anastomosis remains unaffected by the effects of RT because irradiated tissue is resected. Preoperative RT that includes structures that will be resected increases the likelihood that an anastomosis with a healthy colon can be performed. However, one disadvantage of using preoperative RT is the possibility of over-treating early-stage tumors that do not require adjuvant RT. Recent improvements in preoperative staging techniques have allowed for more accurate staging, but the risk of over-staging the disease has not been eliminated [10].

An interval analysis at a median follow-up of 1 year of the first 116 patients enrolled in the NSABP R-03 trial showed an increase in sphincter preservation favoring the preoperative arm ( $44 \%$ vs. $34 \%$ ), with a similar incidence of postoperative toxicities in preand postoperative chemoradiotherapy (chemoRT) arms [3]. Wagman et al. [8] demonstrated that preoperative RT allowed sphincter preservation in $77 \%$ of selected patients who would otherwise have required an abdominoperineal resection and that $85 \%$ of those patients had good to excellent sphincter function. In the CAO/ARO/AIO 94 study, Sauer et al. [7] randomly assigned 805 patients with clinical stage II or III rectal cancer to preoperative or postoperative regimens of chemoRT. With a median follow-up of 4 years, no significant differences between preoperative and postoperative chemoRT were reported in the primary endpoint of 5 -year overall survival (OS) ( $74 \%$ vs. $76 \%, \mathrm{P}=0.32)$. However, treatment compliance ( $92 \%$ vs. $54 \%$; $\mathrm{P}<0.001$ ), grades $3-4$ acute and late toxicity profiles ( $27 \%$ vs. $40 \%, \mathrm{P}=0.001$ ), tumor ( $8 \%$ vs. $0 \%, \mathrm{P}<0.001)$ and nodal ( $25 \%$ vs. $40 \%, \mathrm{P}=0.001)$ downstaging, and rates of pelvic recurrence ( $6 \%$ vs. $13 \%, \mathrm{P}=0.006$ ), all favored the preoperative chemoRT arm. In recently published long-term follow-up data of this trial, the improvement in local control persisted, with the 10-year cumulative incidence of local relapse at $7.1 \%$ and $10.1 \%$ in the preoperative and the postoperative arms, respectively $(\mathrm{P}=0.048)$. Also, in a recent trial, no significant differences were detected for the 10-year cumulative incidences of distant metastases ( $29.8 \%$ vs. $29.6 \%, \mathrm{P}=0.9)$, disease-free survival (DFS) $(68.1 \%$ vs. $67.8 \%, \mathrm{P}=0.65)$, and $\mathrm{OS}(59.6 \%$ vs. $59.9 \%, \mathrm{P}=$ 0.85) [11].

Based on above results, preoperative chemoRT is associated with enhanced sphincter-preservation, significant tumor and nodal downstaging, improved acute and late tolerability, improved local control, and at least similar survival. Therefore, preoperative chemoRT is now considered the standard of care for patients with stages II and III rectal cancer.

\section{LONG-COURSE OR SHORT-COURSE RADIATION}

The best course of neoadjuvant treatment has not yet been determined. Many European investigators over the past two decades have investigated preoperative RT alone for stages II and III rectal cancer, most commonly as a short, high-dose-per-fraction course. However, the United States has not adopted a short-course RT approach because the potential for late radiation morbidity and anorectal dysfunction remains a significant concern with hypofractionation. In the United States, stage II or higher rectal cancers are more commonly treated with preoperative chemoRT consisting of 4,500 to $5,040 \mathrm{cGy}$ of RT in conjunction with infusion fluorouracil 
(5-FU)-based chemotherapy. The RT is delivered over a period of 5 to 6 weeks, and surgery (low anterior resection or abdominal perineal resection) is done 6 to 10 weeks after completion of the radiation therapy. The combination of preoperative RT (usually 4,500 to $5,040 \mathrm{cGy}$ ) with infusion 5-FU-leucovorin (LV) often results in a dramatic reduction in tumor size (or downstaging) and may result in an apparent complete eradication of the tumor in up to $25 \%$ of the cases. Neoadjuvant chemoRT may increase the ability of the surgeon to preserve continence by downstaging the cancer, in some cases shrinking tumor size to permit the achievement of a cancer-free margin at the distal extent of the resection, when a clear margin that will permit an anastomosis in the anal canal cannot be achieved without such shrinkage [4, 12-15].

In Europe, a short course of RT (25 Gy), followed by extirpative surgery (low anterior resection or abdominal perineal resection), is the most common approach. Several European studies have looked at the efficacy of a shorter course of preoperative RT (25 Gy over 5 days), not combined with chemotherapy, for the treatment of rectal cancer. In a Swedish rectal cancer trial, the results showed a survival advantage and a decreased rate of local recurrence with this approach compared with surgery alone [16]. However, a follow-up study showed that short-course preoperative RT had caused relatively increased risk for postoperative hospitalization due to bowel obstructions and other gastrointestinal (GI) complications [17]. Despite improvements in local control of disease, some studies have demonstrated that preoperative short-course RT for rectal cancer patients does not affect their overall survival significantly $[18,19]$. A recent multicenter, randomized study of 1,350 patients with rectal cancer compared short-course preopera- tive RT and no postoperative treatment with no preoperative RT and a postoperative approach that included chemoRT in selected patients (i.e., those with a positive circumferential margin) and no RT in patients without evidence of residual disease following surgery [20]. Results indicated that patients in the preoperative RT arm had significantly lower local recurrence rates and a $6 \%$ absolute improvement in 3-year disease free survival $(\mathrm{P}=0.03)$, although no difference in overall survival was observed between the arms of the study [20, 21]. In a long-term (12-year) follow-up of a Dutch TME trial, preoperative short-course RT reduced the 10year local recurrence by more than $50 \%$ relative to surgery alone, but without an overall survival benefit. This study showed that for patients with TNM stage III cancer with a negative circumferential resection margin, the 10 -year survival was $50 \%$ in the preoperative RT group versus $40 \%$ in the surgery-alone group $(\mathrm{P}=0.032)$. However, this long-term follow-up showed that secondary malignancies and other non-rectal-cancer causes of death were more frequent in the RT than in the control group, negating any survival advantage in the node-negative subpopulation. Nevertheless, the authors concluded that preoperative short-term RT significantly improved the 10-year survival in patients with a negative circumferential margin and TNM stage III cancer [22]. Results from a Polish rectal cancer trial showed that short-term RT was as effective as long-course chemoRT in the aspects of local recurrence and survival [23]. Similarly, in the Trans-Tasman Radiation Oncology Group Trial 01.04 that randomized 326 patients to short-course RT or long-course chemoRT, the 3-year local recurrence rates (cumulative incidence) were $7.5 \%$ for short-course RT and $4.4 \%$ for long-course chemoRT $(\mathrm{P}=0.240)$. The 5-year distant recurrence

Table 1. Oncologic outcomes of short-course radiation therapy and long-course chemoradiotherpay

\begin{tabular}{|c|c|c|c|c|c|c|c|}
\hline Study & Modality & Interval & OS & CSS & DFS & $\mathrm{LC}$ & Late toxicity \\
\hline $\begin{array}{l}\text { Swedish rectal cancer trial } \\
\text { (1997 \& 2005) [17] }\end{array}$ & $\begin{array}{l}\text { SCR + surgery } \\
\text { Surgery alone } \\
\text { P-value }\end{array}$ & $5 \mathrm{yr}$ & $\begin{array}{r}58 \% \\
48 \% \\
0.004\end{array}$ & $\begin{array}{r}74 \% \\
65 \% \\
0.002\end{array}$ & & $\begin{array}{r}11 \% \\
27 \% \\
<0.001\end{array}$ & $\begin{array}{l}\text { Increased readmission } \\
\text { rate in SCR group }\end{array}$ \\
\hline Dutch TME trial (2007) [18] & $\begin{array}{l}\text { SCR + TME } \\
\text { TME alone } \\
\text { P-value }\end{array}$ & $5 \mathrm{yr}$ & $\begin{array}{r}64.2 \% \\
63.5 \% \\
0.902\end{array}$ & $\begin{array}{r}75.4 \% \\
72.4 \% \\
0.260\end{array}$ & & $\begin{array}{r}5.6 \% \\
10.9 \% \\
<0.001\end{array}$ & \\
\hline Dutch TME trial (2011) [22] & $\begin{array}{l}\text { SCR + TME } \\
\text { TME alone } \\
\text { P-value }\end{array}$ & $10 \mathrm{yr}$ & $\begin{array}{l}48 \% \\
49 \% \\
0.86 \\
\end{array}$ & $\begin{array}{r}72 \% \\
69 \% \\
0.200\end{array}$ & $\begin{array}{r}74 \% \\
68 \% \\
0.030\end{array}$ & $\begin{array}{r}5 \% \\
11 \% \\
<0.0001\end{array}$ & \\
\hline Bujko et al. (2006) [23] & $\begin{array}{l}\text { SCR + surgery } \\
\text { LCR + surgery } \\
\text { P-value }\end{array}$ & $4 \mathrm{yr}$ & $\begin{array}{r}67.2 \% \\
66.2 \% \\
0.960\end{array}$ & & $\begin{array}{r}58.4 \% \\
55.6 \% \\
0.820\end{array}$ & $\begin{array}{r}9.0 \% \\
14.2 \% \\
0.170\end{array}$ & $\begin{array}{r}10.1 \% \\
7.1 \% \\
0.360\end{array}$ \\
\hline
\end{tabular}

SCR, short-course radiotherapy; TME, total mesorectal excision; LCR, long-course chemoradiotherapy; OS, overall survival; CSS, cancer-specific survival; DFS, diseasefree survival; LC, local recurrence rate. 
rates were $27 \%$ for short-course RT and 30\% for long-course chemoRT $(\mathrm{P}=0.920)$. The overall survival rates at 5 years were $74 \%$ for short-course RT and 70\% for long-course chemoRT (P = $0.620)$. The late toxicity rates were not substantially different $(\mathrm{P}=$ 0.530) [24]. Additionally, results from an interim analysis of the Stockholm III trial showed that short-course RT in combination with delayed surgery was feasible and had a downstaging effect [25]. Based on the above results, short-course RT appears to provide effective local control and the same OS as more long-course chemoRT schedules and, therefore, may be an appropriate choice in some situations. Table 1 shows a brief summary of the oncologic outcomes of the above trials.

\section{CONCURRENT CHEMORADIATION THERAPY}

In the early 1990s, preoperative RT was considered in most European countries as the standard treatment for T3-4 rectal cancers. Conversely, a National Institutes of Health Consensus Conference stated that postoperative chemoRT should be regarded as the standard treatment for patients with stages II and III rectal cancer. Thus, the evaluation of concurrent chemotherapy and RT had become an attractive field of research. The putative benefits of the addition of chemotherapy concurrent with either pre- or postoperative RT include local RT sensitization and systemic control of disease (eradication of micrometastases). Also, preoperative chemoRT has the potential to increase the rates of pathologic complete response and sphincter preservation [26-32].

In 1993, the European Organisation for Research and Treatment of Cancer (EORTC) initiated a four-arm, randomized trial (EORTC 22921) to examine the value of preoperative chemoRT versus preoperative RT alone and the value of additional chemotherapy versus none with respect to overall survival and progression-free survival. In preliminary results, after preoperative chemoRT, tumors were smaller $(\mathrm{P}=0.0001)$, had less advanced $\mathrm{pT}(\mathrm{P}=0.001)$ and $\mathrm{pN}$ stages $(\mathrm{P}=0.001)$, had small numbers of examined nodes $(\mathrm{P}=$ $0.046)$, and had less frequent lymphovascular or perineural invasions $(\mathrm{P}=0.008)$. Mucinous tumors increased after preoperative chemoRT $(\mathrm{P}=0.001)$ [27]. However, more mature results from EORTC 22921 showed no significant difference in OS between the groups that received chemotherapy preoperatively $(\mathrm{P}=0.840)$ and those that received it postoperatively $(P=0.120)$, and the 5 -year cumulative incidence rates for local recurrences were $8.7 \%$, $9.6 \%$, and $7.6 \%$ in the groups that received chemotherapy preoperatively, postoperatively, or both, respectively, and $17.1 \%$ in the group that did not receive chemotherapy $(\mathrm{P}=0.002)$. The authors indicated that, in patients with rectal cancer who receive preoperative RT, adding 5-FU-based chemotherapy preoperatively or postoperatively had no significant effect on survival. However, they concluded that chemotherapy, regardless of whether it was administered before or after surgery, conferred a significant benefit with respect to local control [28]. The FFCD 9203 trial for patients with T3-4 rectal cancer without evidence of distant metastases showed no difference in sphincter preservation between the preoperative RT alone and the preoperative chemoRT with 5-FU/LV groups. However, complete sterilization of the operative specimen was more frequent with chemoRT $(11.4 \%$ vs. $3.6 \%, \mathrm{P}=0.050)$. The 5-year incidence of local recurrence was lower with chemoRT (8.1\% vs. $16.5 \%$; $\mathrm{P}=0.050)$, but the 5 -year OSs in the two groups were not different [29]. Also, some systematic reviews [30-32] concluded that the addition of chemotherapy to preoperative RT enhanced the pathologic response and improved local control, but had no effect on DFS and OS.

Many chemotherapy regimens have been examined in the adjuvant therapy of rectal cancer, although virtually all have been based on 5-FU. A previously-reported GI intergroup trial of continuous-infusion 5-FU during radiation therapy in an attempt to maximize local control demonstrated no significant improvement in local tumor control, but statistically-significant improvements in DFS and OS compared with bolus 5-FU [33]. However, most of the patients in that study had node-positive disease. On the other hand, the final reports of the Intergroup 0114 [34] and the GI INT 0144 [35] trails demonstrated that similar outcomes with respect to OS and relapse-free survival were observed when an infusion 5-FU or bolus 5-FU/LV was administered concurrently with postoperative RT. Till now, there has been no clinicallymeaningful difference in outcome based on FU-only dose schedule. Also, whether 5-FU is biochemically modulated by LV or administered as protracted venous infusion during part of or the entirety of treatment, outcomes were equivalent.

When postoperative chemoRT is recommended, a "sandwich" approach in which chemotherapy (typically 5-FU-based) is administered before and after the chemoRT regimen may be commonly used $[33,34,36]$. This is because postoperative pelvic radiation may compromise the colorectal or coloanal anastomosis and the function of the neorectum.

\section{Addition of capecitabine}

Capecitabine is an oral fluoropyrimidine derivative that is as effective as 5-FU plus folinic acid for adjuvant treatment of stage III colon cancer [36]. It is also not inferior to infusion 5-FU in combination with oxaliplatin for first-line treatment of metastatic colorectal cancer [37]. Recent studies have shown that capecitabine is equivalent to $5-\mathrm{FU}$ in perioperative chemoRT therapy. Sanghera et al. [38] found similar pathologic complete response rates with capecitabine (17\%) and infusion 5-FU (20\%) in a meta-analysis of 71 trials with a total of 4,732 patients. In 2012, one randomized trial in which 401 patients with stage II or III rectal cancer received capecitabine or 5-FU-based chemoRT either pre- or postoperatively showed that capecitabine was not inferior to 5-FU in perioperative chemoRT therapy [39]. The 5-year OS in the capecitabine group was not inferior to that in the 5-FU group (76\% in the capecitabine group vs. $67 \%$ in the 5 -FU group, noninferiority $\mathrm{P}=0.0004$ ). The effect of capecitabine relative to $5-\mathrm{FU}$ 
was noted for both cohorts, although it was slightly smaller in the neoadjuvant cohort than in the adjuvant cohort (hazard ratio [HR], 1.28; 95\% confidence interval [CI], 0.69-2.37 vs. HR, 1.62; $95 \%$ CI, 0.92-2.86, respectively). Furthermore, in that study, the 3 -year DFS was higher in the capecitabine group than in the 5-FU group (75\% vs. $67 \%, \mathrm{P}=0.070)$ [39]. Based on the above results, capecitabine is an acceptable alternative to infusion 5-FU in those patients who are able to manage the responsibilities inherent in self-administered, oral chemotherapy.

\section{Addition of oxaliplatin}

With optimized local treatment, which can be achieved with preoperative RT or chemoRT and TME surgery, local recurrence rates have been markedly reduced. Another main cause for failure in the treatment of rectal cancer is distant metastases. Any improvement in overall survival will require better control of systemic disease while keeping the rate of local recurrences below $5 \%-10 \%$. Along these lines, several randomized trials have addressed the addition of oxaliplatin to the chemotherapy regimen. The National Surgical Adjuvant Breast and Bowel Project (NSABP) Trial R-04 compared protracted venous infusion 5-FU with capecitabine for preoperative treatment of rectal cancer. Addition of oxaliplatin to either regimen was investigated using a two-by-two factorial design. Preliminary data showed that no differences in the pathologic complete response rates, numbers of sphincter-saving surgery, or surgical down-stagings were seen between regimens with capecitabine and with 5-FU while toxicity was increased with the inclusion of oxaliplatin [39].

In the pathologic results of the STAR-01 trial, grades 3 to 4 adverse events during preoperative treatment were more frequent with oxaliplatin plus 5-FU and RT than with RT and 5-FU alone ( $24 \%$ vs. $8 \%, \mathrm{P}<0.001$ ) while there were no differences in the sphincter-saving rates, the numbers of pathologically positive lymph nodes, the tumor depths, or the pathologically positive circumferential margins. That study reported that adding oxaliplatin to fluorouracil-based preoperative chemoRT significantly increased toxicity without affecting primary tumor response. The OS which is the primary end point of the study will be reported in the future [40].

The ACCORD 12 trial, in which chemoRT with capecitabine was compared to chemoRT with capecitabine and oxaliplatin, showed that at 3 years, there were no significant differences in cumulative incidences of local recurrence (6.1\% vs. $4.4 \%)$, OS $(87.6 \%$ vs. $88.3 \%)$, and DFS (67.9\% vs. $72.7 \%, \mathrm{P}=0.390)$ [41]. The initial results of the German CAO/ARO/AIO-04 randomized phase 3 trial also assessed the addition of oxaliplatin to a 5-FU RT regimen. In contrast to other trials, that study demonstrated that a pathological complete response was achieved in 103 of 591 patients (17\%) who underwent surgery in the 5-FU and oxaliplatin group and in 81 of 606 patients (13\%) who underwent surgery in the 5 -FU group $(\mathrm{P}=0.038)$. However, that finding might have resulted from the differences in the 5-FU schedule between the arms, and long-term follow-up is needed to assess the DFS [42]. Based on the above results, concurrent administration of oxaliplatin and RT is not recommended at this time.

\section{Addition of targeted agents}

The epidermal growth factor receptor (EGFR)-targeted monoclonal antibodies cetuximab and panitumumab have shown efficacy as monotherapy in phase III studies in patients with chemotherapy-refractory metastatic colorectal cancer [43-45]. Preliminary data suggest that EGFR-targeted agents in combination with RT may be synergistic as RT increases EGFR expression within tumor cells while EGFR blockade sensitizes the cells to the effects of RT $[46,47]$. In the setting of locally advanced head and neck cancer, addition of cetuximab to RT enhanced locoregional control and survival $[48,49]$. In the multicenter randomized phase II EXPERT-C trial, a significant improvement in OS was seen in patients with KRAS exon 2/3 wild-type tumors treated with cetuximab $(\mathrm{P}=0.034)$. However, in those patients, the addition of cetuximab did not improve the primary endpoint of complete response $(\mathrm{P}=1.000)$; further evaluation of this regimen is warranted [50]. Another randomized phase II trial, SAKK 41/07, evaluated the efficacy and the safety of panitumumab in combination with capecitabine and external beam RT as a neoadjuvant regimen for patients with wild-type KRAS locally advanced rectal cancer. In that study, although the addition of panitumumab to neoadjuvant chemoRT in patients with KRAS wild-type rectal cancer resulted in a high pathologic nearly complete or complete rate, it increased toxicity [51]. Thus, more well-designed and large-scaled research on the addition of targeted agents to the chemoRT regimen required.

\section{EVALUATION OF TUMOR RESPONSE TO RADIATION THERAPY AFTER PREOPERATIVE RADIATION}

Although pretreatment staging is the standard for planning the treatment regimen for patients with rectal cancer, pathologic stage may be the better prognostic determinant of cancer-related survival. Therefore, improving the understanding of tumor response in the natural history of rectal cancer on the basis of postchemoRT pathology will provide practical information for patients and practitioners who are considering prognosis or who are planning adjuvant treatment. Many investigators demonstrated that $50 \%-$ $60 \%$ of patients are down-staged following preoperative therapy, with $10 \%-30 \%$ of patients showing a pathologic complete response [52-58].

The response after preoperative chemoRT in rectal cancer patients may be associated with their oncologic outcomes. One study in the United State reported that patients who failed to respond to preoperative 5-FU-based chemotherapy given concomitantly with RT had higher rates of distant metastases with adjuvant 5-FU therapy [59]. Another retrospective study demon- 
strated that the pathologically determined response to preoperative treatment correlated with long-term outcomes. In that study, the 5-year recurrence-free survival rates were $90.5 \%, 78.7 \%$, and $58.5 \%$ for patients with complete, intermediate, and poor responses, respectively $(\mathrm{P}<0.001)$. Distant metastases and local recurrences also correlated with the level of response [56]. In the MERCURY trial, magnetic resonance imaging (MRI)-assessed tumor regression grade was significantly associated with overall and disease free survival [60]. Preoperative treatment response may serve as not only an indicator of prognosis but also an indicator of subsequent response to the same chemotherapeutic agents used for radiosensitization among patients with good responses and of the need for expanded therapeutic options for patients with poor response $[28,52]$. Controversy exists as to whether adjuvant chemotherapy should be required for patients with good response to preoperative chemoRT. One study reported that in patients with ypN0 status, the continuation of adjuvant chemotherapy did not improve the prognosis because the prognosis was excellent independent of the adjuvant chemotherapy [55]. However, a subgroup analysis of the EORTC 22921 trial showed that patients down-staged to ypT0-2 were more likely to benefit from adjuvant chemotherapy than patients with ypT3-4 staging [52]. Much to our regret, there are no prospective data to predict the benefit of adjuvant therapy in patients with tumor downstaging or a pathologic complete response.

Recently, some reports in the literature have questioned whether routine imaging for restaging after preoperative chemoRT is needed or not. Most studies have found that neither positronemission tomography-computed tomography (PET-CT), nor MRI, nor CT can accurately determine a pathologic complete response [61-63]. Radiological modalities for staging primary rectal tumors include (CT), endorectal ultrasound (ERUS), and pelvic MR images. At present, fluorine-18-fluorodeoxyglucose PET is widely used in colorectal cancer staging because of its good sensitivity in detecting abnormal metabolism of cancer cells [61]. However, many investigators have demonstrated that the accuracy of restaging with imaging modalities, including CT, ERUS, MRI, or PET-CT, after chemoRT is very low [62]. They proposed that the low accuracy after chemoRT might be attributed to the effects of radiation on the rectal wall or to alterations of the histopathologic morphology in and around the tumor site. Marked fibrosis of the bowel wall resulting from radiation is easily overestimated by images. Another reason for these results might be the peritumoral desmoplastic reaction. Peritumoral infiltration with inflammatory cells or vascular proliferation is found in and around the tumor site. These alterations in histopathologic morphology were correlated with perilesional enhancement by images, often leading to stage overestimation [63]. However, a need exists to restage tumors for a less invasive approach. Downstaging may permit sphincter- or even organ-preserving approaches that include diligent surveillance without resection [64-69]. Local tumor upstaging may necessitate more aggressive procedures, such as a multivisceral resection or pelvic exenteration [70, 71].

In 2004, Habr-Gama et al. [72] retrospectively compared the outcomes of 71 patients who were observed without surgery following a complete clinical response to the outcomes of 22 patients who had incomplete clinical responses but complete pathologic responses after a TME. With re-evaluation using proctoscopy examination by an experienced colorectal surgeon, the absence of significant residual ulcer or positive biopsies performed during proctoscopy were considered as a clinical complete response. The OS and the DFS rates at 5 years were $100 \%$ and $92 \%$ in the nonoperative group compared to $88 \%$ and $83 \%$ in the surgery group. In 2011, a prospective study that used very strict criteria, including MRI and endoscopy plus biopsies, to determine the clinical complete response was published. In that study, only one patient of 21 patients with clinical complete responses who were then observed with careful follow-up developed a local recurrence after a mean follow-up of 25 months; that patient underwent successful salvage surgery. The cumulative probabilities for the 2-year DFS and OS rates were $89 \%$ and $100 \%$, respectively, in the wait-and-see group and $93 \%$ and $91 \%$ in the 20 patients with a complete pathologic response after resection [73].

Despite their impressive results, many investigators still believe that longer follow-up, larger sample sizes, and additional careful observational studies are needed before patients with a clinical complete response are routinely managed by a wait-and-see approach. The rationale of a 'wait-and-see' policy relies mainly on retrospective observations from a single series. Proof of principle in small, low rectal cancers, where clinical assessment is easy, should not be extrapolated uncritically to more advanced cancers where nodal involvement is common. Long-term prospective observational studies with more uniform inclusion criteria are required to evaluate the risk versus benefit.

\section{THE OPTIMAL TIMING OF SURGERY AFTER PREOPERATIVE RADIATION}

One of the unresolved questions concerning preoperative chemoRT for rectal cancer is the timing of surgery. The colorectal surgeon is faced with a dilemma of having to choose between offering immediate radical surgery and interrupting possible ongoing necrosis and further tumor downstaging or offering the possibility of complete tumor regression and nonsurgical management, but with the risk of significantly delaying necessary radical surgery. Therefore, evaluating the outcomes of patients managed by using delayed surgical therapy is fundamental to determine the safety and the potential benefits or harms of this treatment strategy. In terms of tumor downstaging, the Lyon trial showed increased downstaging in the group of patients with delayed RT-to-surgery interval (6-8 weeks from the end of preoperative RT), although this finding did not lead to significantly increased sphincter-preservation rates [74]. Although longer intervals have been shown to be associated with an increase in pathologic complete response rate, whether such longer 
intervals area associated with clinical benefit is unclear [74-78]. Specific reasons may exist for planning a resection at a shorter or a longer interval from end of radiation. A large, bulky tumor showing a good response at evaluation at the end of radiation may be a reason for postponing the resection whereas a progressive disease would necessitate early surgery. Although monitoring the tumor response is difficult, response monitoring may be helpful for tailoring patient management regarding the timing of surgery [77]. Especially, this may be helpful for identifying progressive disease requiring early surgery. In general, for patients treated with preoperative chemoRT, most surgeons recommend an interval of 5 to 12 weeks following the completion of full-dose chemoRT (45-50 Gy) prior to surgical resection in order to allow the patient to recuperate from chemoRT-associated toxicities.

\section{CONCLUSION}

Radiation therapy has long been considered an important adjunct in the treatment of rectal cancer. Based on reports published in the literature, preoperative chemoRT may be better than postoperative chemoRT in the aspects of local control and sphincter preservation, short-course RT may be equivalent to long-course chemoRT in the aspect of oncologic outcome, and concurrent chemoRT may be superior to RT alone in the aspect of long-term survival. Although no prospective data on several issues exist, we hope that in the near future, patients with rectal cancer will be treated by using the best combination of surgery, radiation, and chemotherapy.

\section{CONFLICT OF INTEREST}

No potential conflict of interest relevant to this article was reported.

\section{REFERENCES}

1. Heald RJ, Husband EM, Ryall RD. The mesorectum in rectal cancer surgery: the clue to pelvic recurrence? Br J Surg 1982;69:613-6.

2. Swedish Rectal Cancer Trial. Initial report from a Swedish multicentre study examining the role of preoperative irradiation in the treatment of patients with resectable rectal carcinoma. Br J Surg 1993;80:1333-6.

3. Hyams DM, Mamounas EP, Petrelli N, Rockette H, Jones J, Wieand HS, et al. A clinical trial to evaluate the worth of preoperative multimodality therapy in patients with operable carcinoma of the rectum: a progress report of National Surgical Breast and Bowel Project Protocol R-03. Dis Colon Rectum 1997;40:131-9.

4. Dahlberg M, Glimelius B, Graf W, Pahlman L. Preoperative irradiation affects functional results after surgery for rectal cancer: results from a randomized study. Dis Colon Rectum 1998;41:543-9.

5. Gay HA, Barthold HJ, O’Meara E, Bosch WR, El Naqa I, Al-Lozi R, et al. Pelvic normal tissue contouring guidelines for radiation therapy: a Radiation Therapy Oncology Group consensus panel atlas. Int J Radiat Oncol Biol Phys 2012;83:e353-62.

6. Glimelius B, Graffman S, Pahlman L, Rimsten A, Wilander E. Preoperative irradiation with high-dose fractionation in adenocarcinoma of the rectum and rectosigmoid. Acta Radiol Oncol 1982; 21:373-9.

7. Sauer R, Becker H, Hohenberger W, Rodel C, Wittekind C, Fietkau $\mathrm{R}$, et al. Preoperative versus postoperative chemoradiotherapy for rectal cancer. N Engl J Med 2004;351:1731-40.

8. Wagman R, Minsky BD, Cohen AM, Guillem JG, Paty PP. Sphincter preservation in rectal cancer with preoperative radiation therapy and coloanal anastomosis: long term follow-up. Int J Radiat Oncol Biol Phys 1998;42:51-7.

9. Kachnic LA. Should preoperative or postoperative therapy be administered in the management of rectal cancer? Semin Oncol 2006;33(6 Suppl 11):S64-9.

10. Madoff RD. Chemoradiotherapy for rectal cancer--when, why, and how? N Engl J Med 2004;351:1790-2.

11. Sauer R, Liersch T, Merkel S, Fietkau R, Hohenberger W, Hess C, et al. Preoperative versus postoperative chemoradiotherapy for locally advanced rectal cancer: results of the German CAO/ARO/ AIO-94 randomized phase III trial after a median follow-up of 11 years. J Clin Oncol 2012;30:1926-33.

12. King M, Tolan S, Giridharan S, McConkey C, Hartley A, Geh JI. Late toxicity after short course preoperative radiotherapy and total mesorectal excision for resectable rectal cancer. Clin Oncol (R Coll Radiol) 2003;15:233-6.

13. Peeters KC, van de Velde CJ, Leer JW, Martijn H, Junggeburt JM, Kranenbarg EK, et al. Late side effects of short-course preoperative radiotherapy combined with total mesorectal excision for rectal cancer: increased bowel dysfunction in irradiated patients: a Dutch colorectal cancer group study. J Clin Oncol 2005;23: 6199-206.

14. Bujko K, Rutkowski A, Chang GJ, Michalski W, Chmielik E, Kusnierz J. Is the $1-\mathrm{cm}$ rule of distal bowel resection margin in rectal cancer based on clinical evidence? A systematic review. Ann Surg Oncol 2012;19:801-8.

15. Pollack J, Holm T, Cedermark B, Holmstrom B, Mellgren A. Long-term effect of preoperative radiation therapy on anorectal function. Dis Colon Rectum 2006;49:345-52.

16. Improved survival with preoperative radiotherapy in resectable rectal cancer. Swedish Rectal Cancer Trial. N Engl J Med 1997; 336:980-7.

17. Birgisson H, Pahlman L, Gunnarsson U, Glimelius B; Swedish Rectal Cancer Trial Group. Adverse effects of preoperative radiation therapy for rectal cancer: long-term follow-up of the Swedish Rectal Cancer Trial. J Clin Oncol 2005;23:8697-705.

18. Peeters KC, Marijnen CA, Nagtegaal ID, Kranenbarg EK, Putter $\mathrm{H}$, Wiggers $\mathrm{T}$, et al. The TME trial after a median follow-up of 6 years: increased local control but no survival benefit in irradiated patients with resectable rectal carcinoma. Ann Surg 2007;246: 693-701. 
19. Siegel R, Burock S, Wernecke KD, Kretzschmar A, Dietel M, Loy V, et al. Preoperative short-course radiotherapy versus combined radiochemotherapy in locally advanced rectal cancer: a multi-centre prospectively randomised study of the Berlin Cancer Society. BMC Cancer 2009 Feb 6;9:50.

20. Sebag-Montefiore D, Stephens RJ, Steele R, Monson J, Grieve R, Khanna S, et al. Preoperative radiotherapy versus selective postoperative chemoradiotherapy in patients with rectal cancer (MRC CR07 and NCIC-CTG C016): a multicentre, randomised trial. Lancet 2009;373:811-20.

21. Stephens RJ, Thompson LC, Quirke P, Steele R, Grieve R, Couture $\mathrm{J}$, et al. Impact of short-course preoperative radiotherapy for rectal cancer on patients' quality of life: data from the Medical Research Council CR07/National Cancer Institute of Canada Clinical Trials Group C016 randomized clinical trial. J Clin Oncol 2010;28:4233-9.

22. van Gijn W, Marijnen CA, Nagtegaal ID, Kranenbarg EM, Putter $\mathrm{H}$, Wiggers $\mathrm{T}$, et al. Preoperative radiotherapy combined with total mesorectal excision for resectable rectal cancer: 12-year followup of the multicentre, randomized controlled TME trial. Lancet Oncol 2011;12:575-82.

23. Bujko K, Nowacki MP, Nasierowska-Guttmejer A, Michalski W, Bebenek M, Kryj M. Long-term results of a randomized trial comparing preoperative short-course radiotherapy with preoperative conventionally fractionated chemoradiation for rectal cancer. Br J Surg 2006;93:1215-23.

24. Ngan SY, Burmeister B, Fisher RJ, Solomon M, Goldstein D, Joseph $\mathrm{D}$, et al. Randomized trial of short-course radiotherapy versus long-course chemoradiation comparing rates of local recurrence in patients with $\mathrm{T} 3$ rectal cancer: Trans-Tasman Radiation Oncology Group trial 01.04. J Clin Oncol 2012;30:3827-33.

25. Pettersson D, Cedermark B, Holm T, Radu C, Pahlman L, Glimelius B, et al. Interim analysis of the Stockholm III trial of preoperative radiotherapy regimens for rectal cancer. Br J Surg 2010;97: 580-7.

26. Latkauskas T, Pauzas H, Gineikiene I, Janciauskiene R, Juozaityte E, Saladzinskas Z, et al. Initial results of a randomized controlled trial comparing clinical and pathological downstaging of rectal cancer after preoperative short-course radiotherapy or long-term chemoradiotherapy, both with delayed surgery. Colorectal Dis 2012;14:294-8.

27. Bosset JF, Calais G, Mineur L, Maingon P, Radosevic-Jelic L, Daban A, et al. Enhanced tumorocidal effect of chemotherapy with preoperative radiotherapy for rectal cancer: preliminary resultsEORTC 22921. J Clin Oncol 2005;23:5620-7.

28. Bosset JF, Collette L, Calais G, Mineur L, Maingon P, RadosevicJelic L, et al. Chemotherapy with preoperative radiotherapy in rectal cancer. N Engl J Med 2006;355:1114-23.

29. Gerard JP, Conroy T, Bonnetain F, Bouche O, Chapet O, ClosonDejardin MT, et al. Preoperative radiotherapy with or without concurrent fluorouracil and leucovorin in T3-4 rectal cancers: results of FFCD 9203. J Clin Oncol 2006;24:4620-5.
30. Ceelen WP, Van Nieuwenhove Y, Fierens K. Preoperative chemoradiation versus radiation alone for stage II and III resectable rectal cancer. Cochrane Database Syst Rev 2009;(1):CD006041.

31. McCarthy K, Pearson K, Fulton R, Hewitt J. Pre-operative chemoradiation for non-metastatic locally advanced rectal cancer. Cochrane Database Syst Rev 2012;12:CD008368.

32. De Caluwe L, Van Nieuwenhove Y, Ceelen WP. Preoperative chemoradiation versus radiation alone for stage II and III resectable rectal cancer. Cochrane Database Syst Rev 2013;2:CD006041.

33. O'Connell MJ, Martenson JA, Wieand HS, Krook JE, Macdonald JS, Haller DG, et al. Improving adjuvant therapy for rectal cancer by combining protracted-infusion fluorouracil with radiation therapy after curative surgery. N Engl J Med 1994;331:502-7.

34. Tepper JE, O'Connell M, Niedzwiecki D, Hollis DR, Benson AB 3rd, Cummings B, et al. Adjuvant therapy in rectal cancer: analysis of stage, sex, and local control: final report of intergroup 0114. J Clin Oncol 2002;20:1744-50.

35. Twelves C, Wong A, Nowacki MP, Abt M, Burris H 3rd, Carrato A, et al. Capecitabine as adjuvant treatment for stage III colon cancer. N Engl J Med 2005;352:2696-704.

36. Smalley SR, Benedetti JK, Williamson SK, Robertson JM, Estes NC, Maher T, et al. Phase III trial of fluorouracil-based chemotherapy regimens plus radiotherapy in postoperative adjuvant rectal cancer: GI INT 0144. J Clin Oncol 2006;24:3542-7.

37. Cassidy J, Clarke S, Diaz-Rubio E, Scheithauer W, Figer A, Wong $\mathrm{R}$, et al. Randomized phase III study of capecitabine plus oxaliplatin compared with fluorouracil/folinic acid plus oxaliplatin as first-line therapy for metastatic colorectal cancer. J Clin Oncol 2008;26:2006-12.

38. Sanghera P, Wong DW, McConkey CC, Geh JI, Hartley A. Chemoradiotherapy for rectal cancer: an updated analysis of factors affecting pathological response. Clin Oncol (R Coll Radiol) 2008;20:176-83.

39. Hofheinz RD, Wenz F, Post S, Matzdorff A, Laechelt S, Hartmann JT, et al. Chemoradiotherapy with capecitabine versus fluorouracil for locally advanced rectal cancer: a randomised, multicentre, non-inferiority, phase 3 trial. Lancet Oncol 2012;13:579-88.

40. Aschele C, Cionini L, Lonardi S, Pinto C, Cordio S, Rosati G, et al. Primary tumor response to preoperative chemoradiation with or without oxaliplatin in locally advanced rectal cancer: pathologic results of the STAR-01 randomized phase III trial. J Clin Oncol 2011;29:2773-80.

41. Gerard JP, Azria D, Gourgou-Bourgade S, Martel-Lafay I, Hennequin C, Etienne PL, et al. Clinical outcome of the ACCORD 12/ 0405 PRODIGE 2 randomized trial in rectal cancer. J Clin Oncol 2012;30:4558-65.

42. Rodel C, Liersch T, Becker H, Fietkau R, Hohenberger W, Hothorn $\mathrm{T}$, et al. Preoperative chemoradiotherapy and postoperative chemotherapy with fluorouracil and oxaliplatin versus fluorouracil alone in locally advanced rectal cancer: initial results of the German CAO/ARO/AIO-04 randomised phase 3 trial. Lancet Oncol 2012;13:679-87. 
43. Cunningham D, Humblet Y, Siena S, Khayat D, Bleiberg H, Santoro A, et al. Cetuximab monotherapy and cetuximab plus irinotecan in irinotecan-refractory metastatic colorectal cancer. $\mathrm{N}$ Engl J Med 2004;351:337-45.

44. Douillard JY, Siena S, Cassidy J, Tabernero J, Burkes R, Barugel M, et al. Randomized, phase III trial of panitumumab with infusional fluorouracil, leucovorin, and oxaliplatin (FOLFOX4) versus FOLFOX4 alone as first-line treatment in patients with previously untreated metastatic colorectal cancer: the PRIME study. J Clin Oncol 2010;28:4697-705.

45. Jonker DJ, O'Callaghan CJ, Karapetis CS, Zalcberg JR, Tu D, Au HJ, et al. Cetuximab for the treatment of colorectal cancer. N Engl J Med 2007;357:2040-8.

46. Bonner JA, Maihle NJ, Folven BR, Christianson TJ, Spain K. The interaction of epidermal growth factor and radiation in human head and neck squamous cell carcinoma cell lines with vastly different radiosensitivities. Int J Radiat Oncol Biol Phys 1994;29: 243-7.

47. Liang K, Ang KK, Milas L, Hunter N, Fan Z. The epidermal growth factor receptor mediates radioresistance. Int J Radiat Oncol Biol Phys 2003;57:246-54.

48. Bonner JA, Harari PM, Giralt J, Azarnia N, Shin DM, Cohen RB, et al. Radiotherapy plus cetuximab for squamous-cell carcinoma of the head and neck. N Engl J Med 2006;354:567-78.

49. Bonner JA, Harari PM, Giralt J, Cohen RB, Jones CU, Sur RK, et al. Radiotherapy plus cetuximab for locoregionally advanced head and neck cancer: 5-year survival data from a phase 3 randomised trial, and relation between cetuximab-induced rash and survival. Lancet Oncol 2010;11:21-8.

50. Dewdney A, Cunningham D, Tabernero J, Capdevila J, Glimelius B, Cervantes A, et al. Multicenter randomized phase II clinical trial comparing neoadjuvant oxaliplatin, capecitabine, and preoperative radiotherapy with or without cetuximab followed by total mesorectal excision in patients with high-risk rectal cancer (EXPERT-C). J Clin Oncol 2012;30:1620-7.

51. Helbling D, Bodoky G, Gautschi O, Sun H, Bosman F, Gloor B, et al. Neoadjuvant chemoradiotherapy with or without panitumumab in patients with wild-type KRAS, locally advanced rectal cancer (LARC): a randomized, multicenter, phase II trial SAKK 41/07. Ann Oncol 2013;24:718-25.

52. Collette L, Bosset JF, den Dulk M, Nguyen F, Mineur L, Maingon P, et al. Patients with curative resection of cT3-4 rectal cancer after preoperative radiotherapy or radiochemotherapy: does anybody benefit from adjuvant fluorouracil-based chemotherapy? A trial of the European Organisation for Research and Treatment of Cancer Radiation Oncology Group. J Clin Oncol 2007;25:4379-86.

53. Das P, Skibber JM, Rodriguez-Bigas MA, Feig BW, Chang GJ, Hoff PM, et al. Clinical and pathologic predictors of locoregional recurrence, distant metastasis, and overall survival in patients treated with chemoradiation and mesorectal excision for rectal cancer. Am J Clin Oncol 2006;29:219-24.

54. Das P, Skibber JM, Rodriguez-Bigas MA, Feig BW, Chang GJ,
Wolff RA, et al. Predictors of tumor response and downstaging in patients who receive preoperative chemoradiation for rectal cancer. Cancer 2007;109:1750-5.

55. Fietkau R, Barten M, Klautke G, Klar E, Ludwig K, Thomas H, et al. Postoperative chemotherapy may not be necessary for patients with ypN0-category after neoadjuvant chemoradiotherapy of rectal cancer. Dis Colon Rectum 2006;49:1284-92.

56. Park IJ, You YN, Agarwal A, Skibber JM, Rodriguez-Bigas MA, Eng C, et al. Neoadjuvant treatment response as an early response indicator for patients with rectal cancer. J Clin Oncol 2012;30: 1770-6.

57. Silberfein EJ, Kattepogu KM, Hu CY, Skibber JM, Rodriguez-Bigas MA, Feig B, et al. Long-term survival and recurrence outcomes following surgery for distal rectal cancer. Ann Surg Oncol 2010;17:2863-9.

58. Smith KD, Tan D, Das P, Chang GJ, Kattepogu K, Feig BW, et al. Clinical significance of acellular mucin in rectal adenocarcinoma patients with a pathologic complete response to preoperative chemoradiation. Ann Surg 2010;251:261-4.

59. Janjan NA, Crane C, Feig BW, Cleary K, Dubrow R, Curley S, et al. Improved overall survival among responders to preoperative chemoradiation for locally advanced rectal cancer. Am J Clin Oncol 2001;24:107-12.

60. Patel UB, Taylor F, Blomqvist L, George C, Evans H, Tekkis P, et al. Magnetic resonance imaging-detected tumor response for locally advanced rectal cancer predicts survival outcomes: MERCURY experience. J Clin Oncol 2011;29:3753-60.

61. Guillem JG, Ruby JA, Leibold T, Akhurst TJ, Yeung HW, Gollub MJ, et al. Neither FDG-PET Nor CT can distinguish between a pathological complete response and an incomplete response after neoadjuvant chemoradiation in locally advanced rectal cancer: a prospective study. Ann Surg 2013;258:289-95.

62. Hanly AM, Ryan EM, Rogers AC, McNamara DA, Madoff RD, Winter DC, et al. Multicenter Evaluation of Rectal cancer ReImaging pOst Neoadjuvant (MERRION) Therapy. Ann Surg 2014; 259:723-7.

63. Kuo LJ, Chiou JF, Tai CJ, Chang CC, Kung CH, Lin SE, et al. Can we predict pathologic complete response before surgery for locally advanced rectal cancer treated with preoperative chemoradiation therapy? Int J Colorectal Dis 2012;27:613-21.

64. Janjan NA, Khoo VS, Abbruzzese J, Pazdur R, Dubrow R, Cleary $\mathrm{KR}$, et al. Tumor downstaging and sphincter preservation with preoperative chemoradiation in locally advanced rectal cancer: the M. D. Anderson Cancer Center experience. Int J Radiat Oncol Biol Phys 1999;44:1027-38.

65. Martin ST, Heneghan HM, Winter DC. Systematic review of outcomes after intersphincteric resection for low rectal cancer. Br J Surg 2012;99:603-12.

66. Kim CJ, Yeatman TJ, Coppola D, Trotti A, Williams B, Barthel JS, et al. Local excision of T2 and T3 rectal cancers after downstaging chemoradiation. Ann Surg 2001;234:352-8.

67. Bonnen M, Crane C, Vauthey JN, Skibber J, Delclos ME, Rodri- 
guez-Bigas $\mathrm{M}$, et al. Long-term results using local excision after preoperative chemoradiation among selected $\mathrm{T} 3$ rectal cancer patients. Int J Radiat Oncol Biol Phys 2004;60:1098-105.

68. Smith FM, Chang KH, Sheahan K, Hyland J, O'Connell PR, Winter DC. The surgical significance of residual mucosal abnormalities in rectal cancer following neoadjuvant chemoradiotherapy. Br J Surg 2012;99:993-1001.

69. Martin ST, Heneghan HM, Winter DC. Systematic review and meta-analysis of outcomes following pathological complete response to neoadjuvant chemoradiotherapy for rectal cancer. Br J Surg 2012;99:918-28.

70. Smith JD, Nash GM, Weiser MR, Temple LK, Guillem JG, Paty PB. Multivisceral resections for rectal cancer. Br J Surg 2012;99: 1137-43.

71. Gannon CJ, Zager JS, Chang GJ, Feig BW, Wood CG, Skibber JM, et al. Pelvic exenteration affords safe and durable treatment for locally advanced rectal carcinoma. Ann Surg Oncol 2007;14:1870-7.

72. Habr-Gama A, Perez RO, Nadalin W, Sabbaga J, Ribeiro U Jr, Silva e Sousa AH Jr, et al. Operative versus nonoperative treatment for stage 0 distal rectal cancer following chemoradiation therapy: long-term results. Ann Surg 2004;240:711-7.

73. Maas M, Beets-Tan RG, Lambregts DM, Lammering G, Nelemans PJ, Engelen SM, et al. Wait-and-see policy for clinical complete responders after chemoradiation for rectal cancer. J Clin
Oncol 2011;29:4633-40.

74. Francois Y, Nemoz CJ, Baulieux J, Vignal J, Grandjean JP, Partens$\mathrm{ky} \mathrm{C}$, et al. Influence of the interval between preoperative radiation therapy and surgery on downstaging and on the rate of sphincter-sparing surgery for rectal cancer: the Lyon R90-01 randomized trial. J Clin Oncol 1999;17:2396.

75. Habr-Gama A, Perez RO, Proscurshim I, Nunes Dos Santos RM, Kiss D, Gama-Rodrigues J, et al. Interval between surgery and neoadjuvant chemoradiation therapy for distal rectal cancer: does delayed surgery have an impact on outcome? Int J Radiat Oncol Biol Phys 2008;71:1181-8.

76. Moore HG, Gittleman AE, Minsky BD, Wong D, Paty PB, Weiser $\mathrm{M}$, et al. Rate of pathologic complete response with increased interval between preoperative combined modality therapy and rectal cancer resection. Dis Colon Rectum 2004;47:279-86.

77. Sloothaak DA, Geijsen DE, van Leersum NJ, Punt CJ, Buskens CJ, Bemelman WA, et al. Optimal time interval between neoadjuvant chemoradiotherapy and surgery for rectal cancer. Br J Surg 2013; 100:933-9.

78. Tulchinsky H, Shmueli E, Figer A, Klausner JM, Rabau M. An interval $>7$ weeks between neoadjuvant therapy and surgery improves pathologic complete response and disease-free survival in patients with locally advanced rectal cancer. Ann Surg Oncol 2008; 15:2661-7. 